\title{
Research on the Tourism Space Structure in Lingui District of Guilin Based on the Development and Utilization of Landscape Resources
}

\author{
Zhengmin Wen ${ }^{1,2, *},{ }^{,}$ie $\mathrm{Shi}^{2}$,Shuangbao Qian ${ }^{2}$ and Qing $\mathrm{Xu}^{2}$ \\ ${ }^{1}$ Architecture College, Xi'an University of Architecture and Technology, Xi'an, 710055,Cnina; \\ ${ }^{2}$ School of Civil Engineering and Architecture, Guilin University of Technology, Guilin, 541004, China
}

\begin{abstract}
The 257 scenic spots in Lingui covered 5 main categories, 14 sub-categories and 26 basic types, in which there were 33 natural scenic spots and 224 humanistic scenic spots, featured by rich resources stock, humanistic landscape resources-based, and significant space agglomeration; the quality levels are 11 high-quality scenic spots that most of them have been developed, 57 good scenic spots and 189 ordinary scenic spots that have big development potential; of the 36 scenic spots developed so far, 7 are natural, and 29 are humanistic(22 of them have been oriented by cultural relic protection sites); from initial scattered-point to intensive scattered-point to point-axis period, they showed stepped and multi-center structure situation. We found that: 1) five levels of growth pole have been formed; 2) The influence mechanism of development on tourism space is: the theme park is the greatest, the natural landscape resources is secondary and the cultural landscape resources is the least, the former-residence -type cultural relics protection sites and traditional villages have a certain influence, and the influence of high-level landscape resources is big in general. Based on the above results, we can build the tourism space structure with "one ring, one core, one sub-core, and three axes".
\end{abstract}

\section{Introduction}

The types of landscape resources are diversified and the quantity is rich. In recent years, the pace of development and utilization has speeded up, and the tourism space structure has changed accordingly; however, there exist unclear landscape resources, as well as unclear mechanism of the influence of landscape resources development and utilization on regional tourism space structure, not conducive to construct reasonable regional tourism space structure and promote tourism development.

Some scholars have researched the tourism space. $\mathrm{Wu}$ Bihu, et al. (1994) used different ways to classify the national tourism space, making a useful attempt for the relevant scholars to explore the space development models of tourism in different regions ${ }^{[1]}$. Han Jie (1992) made a classified research on the northeast China's tourism space [2]. Zhang Jixian, et al. (1988) made corresponding researches on tourism development area of central and western China respectively [3]. Many scholars have conducted empirical researches on Shaanxi, Three Gorges reservoir area, Hunan, etc. from diverse perspectives. Zhao Rong(1999) researched the tourism space in Guanzhong area, and analyzed the travel destination and trip space of Xi'an residents ${ }^{[4]}$; Ma Yaofeng (1999) discussed and analyzed the space transference mode of overseas tourists of Xi' an ${ }^{[5]}$; Zhang
Liming ${ }^{[6]}$ (2000), Li Guoping et al. ${ }^{[7]}$ (2001) put forward development strategies for the cause and evolution of the Three Gorges reservoir Region; Xu Chunxiao put forward the development pattern of tourism space in Hunan to guide the reasonable development of regional tourism space; Liu Weiqiang(1993) researched the tourism space of Dali ${ }^{[8]}$; Bao Jigang (2002) researched Guilin tourist space ${ }^{[9]}$; Tian Zhimei(2005) researched the space structure optimization of tourism of Shanxi. However, based on the perspective of "development and utilization of regional landscape resources", there are few researches on the space structure of regional tourism.

In Part 1, After supplementing the basic types of Classification, Investigation and Evaluation of Tourism Resources from the perspective of urban and rural planning, the landscape resources in Lingui District were classified and the characteristics were analyzed and the quality level system of landscape resources was built. In Part 2, the author combed the development and utilization of landscape resources and evolution characteristics of regional tourism space structure from space, time and structure dimensions; based on this, through the comprehensive development evaluation of scenic spots, the author researched the influence mechanism of the former on the latter. In the influence mechanism of the former on the latter. In Part 3, based on the research results of Part 1 and Part 2, the author built the tourism space structure in Lingui District. 


\section{Classification and Evaluation of Landscape Resources}

\subsection{Classification and Distribution}

The perspective of classification of landscape resources is diverse. Classification, Investigation and Evaluation of
Tourism Resources is a national classification standard, and it divided the landscape resources into eight main categories, 31 sub-categories and 155 basic types [11]. This paper started from the perspective of urban and rural planning, and supplemented the basic types to 166 . According to this, the classification of 257 scenic spots in Lingui District was shown in Table 2.1.

Table 2.1. Classification Statistics of Landscape Resources in Lingui District

\begin{tabular}{|c|c|c|c|c|c|c|c|c|c|c|c|c|c|c|c|}
\hline \multirow{2}{*}{$\begin{array}{l}\text { Main } \\
\text { category }\end{array}$} & \multirow{2}{*}{$\begin{array}{c}\text { Sub- } \\
\text { category }\end{array}$} & \multirow{2}{*}{$\begin{array}{l}\text { Basic } \\
\text { type }\end{array}$} & \multirow{2}{*}{$\begin{array}{l}\text { Sub- } \\
\text { type }\end{array}$} & \multicolumn{11}{|c|}{ Landscape resources in Lingui district(township) } & \multirow[b]{2}{*}{ Total } \\
\hline & & & & Lg & $N b$ & $L t$ & $H \boldsymbol{x}$ & $S t$ & $L j$ & Cd & $W t$ & $Z y$ & $W n$ & Hs & \\
\hline \multirow[t]{5}{*}{ A } & AA & AAA & & & & 2 & 1 & & & & & & & & 3 \\
\hline & & AAD & & & & & & & & & 1 & & & & 1 \\
\hline & $\mathrm{AC}$ & $\mathrm{ACC}$ & & 1 & & & 1 & & & & & & & & 2 \\
\hline & & ACG & & & & & & & & & & & 1 & & 1 \\
\hline & & ACL & & 2 & & & 1 & 1 & & & 1 & & & & 5 \\
\hline \multirow[t]{5}{*}{ B } & BA & BAA & & 1 & & & & 1 & & & 3 & & 1 & 1 & 7 \\
\hline & & BAC & & & & & 1 & & & & & & & & 1 \\
\hline & $\mathrm{BB}$ & $\mathrm{BBA}$ & & & 1 & & & & & & 3 & & & & 4 \\
\hline & & $\mathrm{BBB}$ & & & & & 1 & & & & & & & & 1 \\
\hline & $\mathrm{BC}$ & BCA & & & & & & & & & & 1 & 4 & & 5 \\
\hline \multirow[t]{2}{*}{$\mathrm{C}$} & $\mathrm{CA}$ & CAA & & & & & & & & 1 & & & & 1 & 2 \\
\hline & CB & CBA & & & & & 1 & & & & & & & & 1 \\
\hline \multirow[t]{3}{*}{$\mathrm{E}$} & EA & EAA & & & & 1 & 1 & 3 & 1 & & & & & & 6 \\
\hline & EB & EBA & & 1 & 1 & & & 1 & 1 & & & & & & 4 \\
\hline & & EBB & & & & & & & & 1 & 1 & & & & 2 \\
\hline \multirow[t]{18}{*}{$\mathrm{F}$} & FA & FAC & FACA & & & 1 & 1 & 2 & & & 1 & & & & 5 \\
\hline & & & FACD & 2 & 3 & 1 & 1 & 2 & & & & & & & 9 \\
\hline & & & FACE & & 2 & & 3 & 2 & 3 & 3 & 1 & 2 & & & 16 \\
\hline & & & FACG & & & & & & & 1 & 1 & & & & 2 \\
\hline & & FAD & FADA & & & & & & 1 & & & & & & 1 \\
\hline & & & FADB & 1 & & 1 & & & & & & & & & 2 \\
\hline & & & FADC & & & & & & & & 1 & & & & 1 \\
\hline & $\mathrm{FC}$ & FCB & & 1 & & & & 1 & 1 & & & 1 & & & 4 \\
\hline & & $\mathrm{FCC}$ & & & & & & 2 & & 3 & & 1 & 1 & & 7 \\
\hline & & FCF & & & 2 & & & 4 & & 2 & 2 & & & & 10 \\
\hline & & FCG & & & & & 2 & 1 & & & & & & & 3 \\
\hline & & FCK & & & 2 & & 2 & 5 & 1 & 3 & 2 & & 1 & & 16 \\
\hline & FD & FDA & FDAA & & 1 & & 3 & 3 & 4 & 1 & 2 & & 1 & 1 & 16 \\
\hline & & & FDAB & & 9 & 6 & 8 & 9 & 13 & 9 & & 3 & & 3 & 60 \\
\hline & & FDD & & & & 3 & 2 & 2 & 1 & & & & & & 8 \\
\hline & FE & FEA & & & & & 1 & & & & & & & & 1 \\
\hline & $\mathrm{FF}$ & FFA & & 4 & 6 & 9 & 12 & 8 & 2 & 4 & 4 & 2 & & & 51 \\
\hline & Total & & & 13 & 27 & 24 & 42 & 47 & 28 & 28 & 23 & 10 & 9 & 6 & 257 \\
\hline
\end{tabular}

Data Source: collected according to Research on development, utilization and protection of landscape resources in Guilin ${ }^{[12]}$

Here:

A:Physiographic landscape

AA: Integrated Nature Tourist Destination

AC: Trace of Geological and Geomorphological process

AAA: Hill tourist destination AAD: Beach tourist destination ACC: Peak cluster ACG: Canyon reach

ACL: Rock cave and cave

B:Water Area landscape

BA: Reach BB: Natural Lake and Pond BC: Waterfall

BAA: Sightseeing and recreation reach

BAC: Ancient river reach

BBA: Sightseeing recreation

BBB: Swamp and wetland

BCA: Suspended waterfall

C:Biological landscape
CA: Tree CB: Prairie and Grassland

CAA: Forest CBA: Grassland

E:Site and Relic

EA: Prehistoric Place of human activities

EB: Relic of social Economic

EAA: Site of human activities

EBA: Site of historical events

EBB: Military ruins and ancient battlefields

F:Construction and Facility

FA: Comprehensive humanistic tourist destination

FC: The architecture of Landscape and ancillary

FD: Residence and Community FE: Burial ground

FF: Traffic construction

FAC: Place of religion and ritual activities

FAD: Garden recreation area

FCB: Tour-shape architecture

FCC: Pavilion FCF: Castle

FCG: Cliff calligraphy and painting

FCK: Architectural sketch 
FDA: Traditional and local architecture

FDD: Celebrity houses and historic memorial architecture

FEA: Burial area and cemetery FFA: Bridge

FACA: Temple FACD: Native temple

FACE: Ancestral temple FACG: Place of sacrifice

FADA: Theme park FADB: Zoo

FADC:

Botanic

garden

FDAA: Featured tribe FDAB: Residence

For the convenience of expression, this article provides:
$\boldsymbol{L g}$ :Lingui
$\boldsymbol{N b}$ :Nanbianshan
$\boldsymbol{L t}$ :Liutang
$\boldsymbol{H} \boldsymbol{x}$ :Huixian
St:Sitang
Cd:Chadong
Wt:Wutong
$\boldsymbol{L} \boldsymbol{j}$ :Liangjiang
$\boldsymbol{Z y}$ :Zhongyong

$\boldsymbol{W n}$ :Wantia

$\boldsymbol{H u}$ :Huangsha

It's characteristics are as follows:

The 5 main categories, 14 sub-categories and 26 basic types accounts for $62.50 \%, 45.16 \%$, and $15.66 \%$ respectively. The main categories include three types of natural landscape resources (physiographic, water area , and biological ) and two types of humanistic landscape resources (site and relic, architecture and facility); the sub-categories include seven types of natural landscape resources and seven types of humanistic landscape resources; the basic types include 12 types of natural landscape resources and 14 types of humanistic landscape resources.

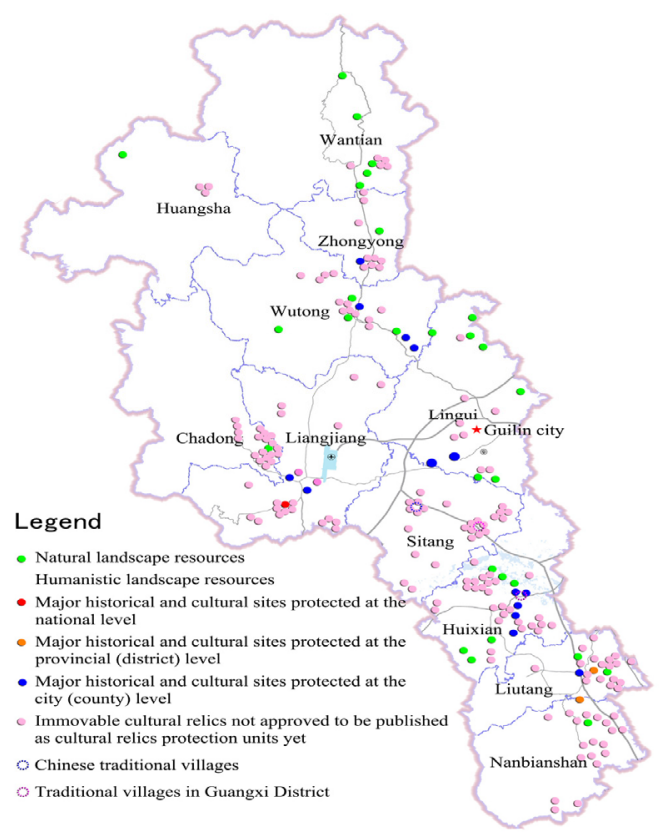

Figure 2.1. Current Distribution Status of Landscape Resources in Lingui District (2015)

The total quantity of landscape resources is rich, dominated by humanistic landscape resources. The 257 scenic spots include 33 natural scenic spots and 224 humanistic scenic spots, accounting for $12.84 \%$ and $87.16 \%$ respectively. For humanistic landscape resources, "ancestral temple", "residential building", "architectural sketch and bridge", etc., which can reflect the local culture, are in the majority.

The space agglomeration is significant. The 11 townships all have a certain number of landscape resources distribution, but they are mainly distributed in $\boldsymbol{H x}, \boldsymbol{C d}, \boldsymbol{N b}, \boldsymbol{L j}, \boldsymbol{W t}, \boldsymbol{L g}$, and $\boldsymbol{S t}$; in space, it shows the distribution trend of five agglomeration zones, namely, $\boldsymbol{W n}, \boldsymbol{Z} \boldsymbol{y}$, National Road $321^{\#}$ of $\boldsymbol{W t}$, agglomeration zone in banks of Yijiang (Yijiang Agglomeration Zone), agglomeration zone in adjacent area of $\boldsymbol{L} \boldsymbol{j}$ and $\boldsymbol{C d}(\boldsymbol{L} \boldsymbol{j}-\boldsymbol{C d}$ Agglomeration Zone), agglomeration zone in adjacent area of $\boldsymbol{S t}$ and $\boldsymbol{L} \boldsymbol{g}(S t-L g$ Agglomeration Zone), $\boldsymbol{H} \boldsymbol{x}$ Agglomeration Zone, agglomeration zone in adjacent area of $\boldsymbol{L t}$ and $\boldsymbol{N b}$ ( $\boldsymbol{L t}-\mathbf{N b}$ Agglomeration Zone), as shown in Figure 2.1.

\subsection{Rating and Distribution}

On the basis of the scoring criteria of evaluation illustrated in Classification, Investigation and Evaluation of Tourism Resources, the value of elements, influence and value-influencing factors suitable for tourism or recreational development of 257 scenic spots were evaluated. The results were evaluated into five grades, as shown in Table 2.2, and its characteristics were as follows.

Table 2.2. Statistics of Rating Results of Landscape Resources in Lingui District, Guilin City

\begin{tabular}{|c|c|c|c|c|c|c|c|c|c|c|c|c|c|}
\hline \multirow[b]{2}{*}{ Grade } & \multicolumn{11}{|c|}{ Township } & \multirow[b]{2}{*}{ Quantity } & \multirow[b]{2}{*}{ Ratio } \\
\hline & Lg & $\mathrm{Nb}$ & $\mathrm{Lt}$ & $\mathrm{Hx}$ & St & $\mathrm{Lj}$ & $\mathrm{Cd}$ & $\mathrm{Wt}$ & $\mathrm{Zy}$ & Wn & $\mathrm{Hs}$ & & \\
\hline I & 1 & & & 1 & & 2 & & & & 1 & & 5 & $1.95 \%$ \\
\hline II & & & 1 & 1 & 2 & & & 1 & & 1 & & 6 & $2.33 \%$ \\
\hline III & 2 & & 2 & 3 & 3 & 1 & 2 & 6 & 3 & 6 & 1 & 29 & $11.29 \%$ \\
\hline IV & 2 & 2 & 5 & 3 & 3 & 4 & 1 & 7 & & 1 & 1 & 29 & $11.29 \%$ \\
\hline Sub total & 5 & 2 & 8 & 8 & 8 & 7 & 3 & 14 & 3 & 9 & 2 & 69 & $26.85 \%$ \\
\hline
\end{tabular}




\begin{tabular}{|cccccccccccc}
$\mathrm{V}$ & 8 & 25 & 16 & 34 & 39 & 21 & 25 & 9 & 7 & 4 & 188 \\
Total & 13 & 27 & 24 & 42 & 47 & 28 & 28 & 23 & 10 & 9 & 6 \\
\hline
\end{tabular}

Data source: collected according to Research on development, utilization and protection of landscape resources in Guilin ${ }^{[12]}$

There are a certain number of high-quality landscape resources, more good landscape resources and the most ordinary landscape resources. There are 11 high-quality landscape resources belonging to Grade I and Grade II, 58 good scenic spots belonging to Grade III and Grade IV, accounting for $22.57 \%$; there are a number of humanistic landscape resources, which although have historical and cultural value, got low scores in scoring items of "ornamental and recreational use value", "historical, cultural, scientific and art value", "scale, abundance and probability", "popularity and influence", "appropriate tour period or serviceable range" due to high repair costs, low entity integrity. It was rated as the fifth grade, a total of 188

scenic spots, accounting for $73.15 \%$.
High-quality and good landscape resources are distributed in aggregation, mainly in the northern $\boldsymbol{S t}, \boldsymbol{W t}$, $\boldsymbol{W n}, \boldsymbol{L j}, \boldsymbol{L g}$, and the southern $\boldsymbol{H x}, \boldsymbol{L t}$.

\section{The Influence Mechanism of Development and Utilization of Landscape Resources on Tourism Space}

\subsection{Features of Development and Utilization of Landscape Resources}

As of 2015 , the number of developed and utilized scenic spots was 36, as shown in Table 3.1. The characteristics were as follows.

Table 3.1. Statistics of Development and Utilization in Landscape Resources in Lingui District

\begin{tabular}{|c|c|c|c|c|c|c|c|c|c|c|c|c|c|c|c|}
\hline & \multicolumn{7}{|c|}{ Humanistic } & \multirow[t]{2}{*}{ Natural } & Humanistic & Natural & Humanistic & \multicolumn{2}{|c|}{ Natural } & \multicolumn{2}{|r|}{ Total } \\
\hline & $L g$ & $N b$ & $L t$ & $H x$ & St & $L j$ & $C d$ & & $W t$ & & $Z y$ & $W n$ & Hs & Natural & Humanistic \\
\hline 1978 & & & & & & & & & & & & & 1 (I) & 1 & \\
\hline 1986 & & $1(\mathrm{~V})$ & 2 (IV) & $1(\mathrm{~V})$ & 1 (IV) & $\begin{array}{c}1 \text { (I) } \\
1 \text { (IV) }\end{array}$ & $2(\mathrm{~V})$ & & 1（III） & & & & & & 10 \\
\hline 1993 & (III) & & & & & & & & & & & & & & 1 \\
\hline 2001 & & & & 1（III） & 1（V） & & & & & & & & & & 2 \\
\hline 2003 & & & 1（II） & & & & & & & & & 1（III） & & 1 & 1 \\
\hline 2004 & & & & & & & & & & & & 1 (II) & & 1 & \\
\hline 2006 & & & & & & & & & & 1（III） & & & & 1 & \\
\hline 2007 & & & & 2(V) & & & & 1（III） & 2(IV) & & $1(\mathrm{~V})$ & & & 1 & 5 \\
\hline 2010 & & & & & & & & 1（II） & & 1（III） & & & & 2 & \\
\hline 2011 & (V) & & & $\begin{array}{l}1 \text { (IV) } \\
1 \text { (V) }\end{array}$ & & 1 (IV) & & & & & & & & & 4 \\
\hline 2013 & & & & & & 1（I） & & & & & & & & & 1 \\
\hline 2015 & 1（I） & & & $\begin{array}{l}1 \text { (II) } \\
1(\mathrm{~V})\end{array}$ & 2 (II) & & & & & & & & & & 5 \\
\hline Total & 3 & 1 & 3 & 8 & 4 & 4 & 2 & 2 & 3 & 2 & 1 & 2 & 1 & 7 & 29 \\
\hline
\end{tabular}

Note: four first-grade scenic spots, six second-grade scenic spots, seven third-grade scenic spots, eight fourth-grade scenic spots, 11 fifth-grade scenic spots, a total of 36 scenic spots.

Data source: collected according to Research on development, utilization and protection of landscape resources in Guilin ${ }^{[12]}$

1)Dominated by cultural relic protection units of humanistic landscape resources.

Among the developed and utilized landscape resources, the number of natural and humanistic scenic spots was seven and 29 respectively, accounting for $19.44 \%$ and $80.56 \%$. Humanistic scenic spots are dominated by cultural relic protection units, up to 22 , accounting for $73.33 \%$; in the 23 cultural relic protection units, 22 have been developed, including one state-level unit, namely, Residence of Li Zongren in Liangjiang, and two autonomous-region-level units, namely, Shuangfeng Bridge in Nanbianshan and Liutang Mosque. The rest are municipal-level and county-level units.
2) The high-quality landscape resources have been developed almost, and good and ordinary landscape resources has huge development potential.

Among the developed and utilized landscape resources, there were 10 high-quality scenic spots, 15 good scenic spots, and 11 ordinary scenic spots, accounting for $90.91 \%, 26.32 \%$, and $6.92 \%$ of the corresponding level of the total number respectively; the former has been basically developed, and for undeveloped scenic spots, there were 42 and 178 ordinary scenic spots, having huge development potential.

3)Uneven Distribution

The developed and utilized landscape resources are mainly distributed in $\mathbf{H x}, \mathbf{W t}, \mathbf{L j}$, and $\mathbf{S t}$ town.

\subsection{Characteristics of Space Structural Evolution of Tourism Industry}

1) The initial period of scattered-point spatial distribution 


\section{(1978-1986)}

In 1978, the state-level nature reserve-Huaping Nature Reserve was established in $\boldsymbol{H s}$; in 1986, the first batch of cultural relic protection units were approved, including Former Residence of Li Zongren in $\boldsymbol{L} \boldsymbol{j}, \boldsymbol{L} \boldsymbol{j}$ Town Brick Tower, the Mosque in $\boldsymbol{W t}$, Bulwark of Shimendang Village in $\boldsymbol{H} \boldsymbol{x}$ and Road Monument for Village Construction, Bulwark of Chucun Village in $\boldsymbol{C d}$, Chastity Arch of Mrs. Shi, St Hengshan Stone Carving, the Mosque in $\boldsymbol{L} \boldsymbol{t}$, Jixiang Bridge, the Shuangfeng Bridge in $\mathbf{N b}$, a total of 10 humanistic scenic spots. In this period, the landscape resources showed scattered-point space distribution.

2) Intensive Period of Scattered-point Spatial Distribution (1987-2002)

Four scenic spots were developed, all belonging to humanistic landscape resources, including Xiongsen Bear \& Tiger Mountain Village, Snake King Li Manor, and $\boldsymbol{S t}$ Dayan Ancient Cultural Relic, Former Residence of Baichongxi in $\boldsymbol{H} \boldsymbol{x}$. The latter two scenic spots were approved as the second batch of cultural relic protection units in 2001. The spatial distribution is intensive.

By 2015, there were 15 developed and utilized scenic spots, showing scattered-point spatial distribution overall. The extensive influence was small, and few links were existed between scenic spots, not forming direct and effective tourism industry space units.

3) The Formation Period of Point-Axis Space (2003-2015)

In this period, there were 21 newly developed scenic spots, including six natural scenic spots and 15 humanistic scenic spots. The six natural scenic spots include Butterfly Valley, Twelve Beach Drift, Lianhua Island, Liu Sanjie Tea Garden, Yijiangyuan and Hongxi Scenic Spot. In the 12 approved scenic spots of the third batch of cultural relic protection units, 11 were developed, which broke the scattered-point spatial distribution pattern, forming a multi-center balanced development model of tourism.

As shown in Figure 2.2 the tourism spatial distribution of 2015 showed the following characteristics.

(1) Stepped Distribution

The space development of tourism showed stepped distribution. The central and southern $\boldsymbol{H} \boldsymbol{x}$ and central and northern $\boldsymbol{W} \boldsymbol{t}$ had the most developed scenic spots, becoming the first gradient of regional tourism distribution; the central $\boldsymbol{L j}, \boldsymbol{S t}, \boldsymbol{L g}$, the northern $\boldsymbol{Z} \boldsymbol{y}$, and the southern $\boldsymbol{L} t$ had relatively more scenic spots, becoming the second gradient; at the outskirts of the first gradient and the second gradient, including the northern $\boldsymbol{W n}, \boldsymbol{H s}$, the western $\boldsymbol{C d}$, and the southern $\boldsymbol{N b}$, the density of the space layout of tourism is low, becoming the third gradient.

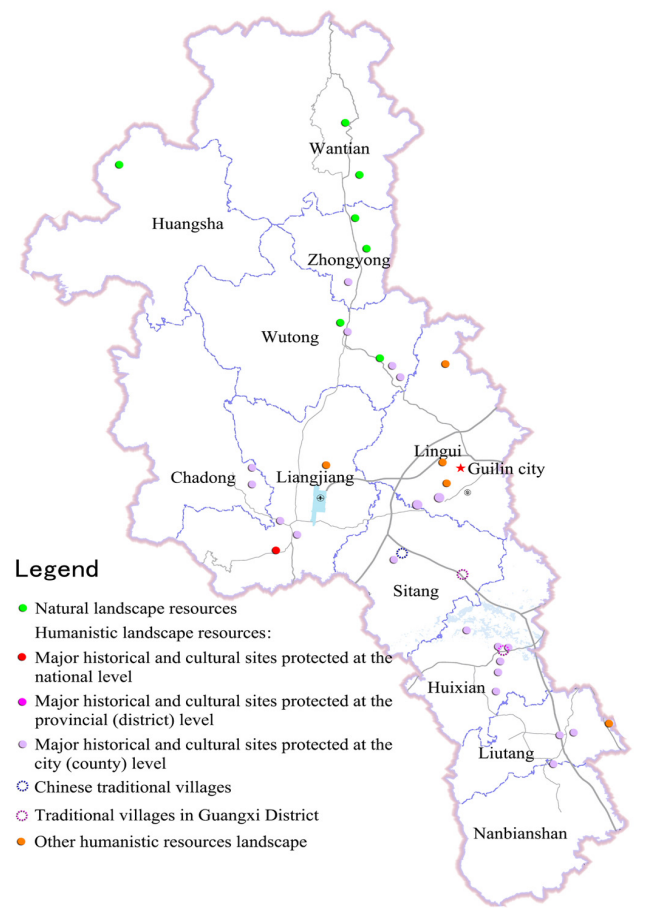

Figure 2.2. Distribution Map of Developed and Utilized Landscape Resources in Lingui District (2015)

(2) Multi-center Developing Structure

The natural landscape resources in the north are superior in conditions, forming tourism spatial distribution area of natural landscape resources; the humanistic landscape resources in the south are superior in conditions, forming tourism spatial distribution area of humanistic landscape resources; the two areas complete each other and form the magnetic double core of regional tourism. The central area enjoys the advantages of the two sides; relying on

superior geographical conditions and infrastructure conditions, developing natural and humanistic resources together, forming the core area of tourism. The three areas promote and supplement each other, laying the basic space structure of regional tourism.

\subsection{Influence Mechanism of Landscape Resource Development and Utilization on Tourism Space Structure}

In order to clarify the competitiveness of developed and utilized scenic spots and their "contribution" to tourism space, the competitiveness evaluation index system of scenic spot needs building and the comprehensive development capacity of scenic spot needs calculating.

1) Comprehensive Index System of Tourism Space Structure

Comprehensively considering the scientificity, accessibility, objectivity, and comparability of scenic spot evaluation system, the competitiveness evaluation index system of scenic spot was built, as shown in Table 3.2.

Table 3.2. Evaluation Index Weight Value of Scenic Spots in Lingui District

\begin{tabular}{|cccccc|}
\hline Target & First-grade index & Weight & & Second-grade index \\
Competiti & Performance & 0.128 & 1 & The number of tourists yearly \\
veness of & competitiveness & & 2 & The number of overseas tourists yearly & 0.044 \\
\hline
\end{tabular}




\begin{tabular}{|c|c|c|c|c|c|}
\hline \multirow{24}{*}{$\begin{array}{c}\text { scenic } \\
\text { spot }\end{array}$} & & & 3 & Annual tourism income & 0.048 \\
\hline & \multirow{3}{*}{$\begin{array}{l}\text { Market } \\
\text { competitiveness }\end{array}$} & \multirow{3}{*}{0.148} & 4 & The number of provincial tourists yearly & 0.0485 \\
\hline & & & 5 & The number of domestic non-provincial tourists yearly & 0.0485 \\
\hline & & & 6 & Market recognition & 0.051 \\
\hline & \multirow{5}{*}{$\begin{array}{l}\text { Resource } \\
\text { competitiveness }\end{array}$} & \multirow{5}{*}{0.176} & 7 & Ornamental and recreational use value & 0.0323 \\
\hline & & & 8 & Historical, cultural, scientific, and art value & 0.0321 \\
\hline & & & 9 & Degree of rarity and peculiarity & 0.0366 \\
\hline & & & 10 & Scale, abundance, and probability & 0.0368 \\
\hline & & & 11 & Integrity & 0.0382 \\
\hline & \multirow{2}{*}{$\begin{array}{l}\text { Talent } \\
\text { competitiveness }\end{array}$} & \multirow{2}{*}{0.108} & 12 & $\begin{array}{l}\text { The proportion of staff with college degree or higher to the total number of } \\
\text { employees }\end{array}$ & 0.05 \\
\hline & & & 13 & $\begin{array}{l}\text { The proportion of management and technical staff to the total number of } \\
\text { employees }\end{array}$ & 0.058 \\
\hline & \multirow{3}{*}{$\begin{array}{l}\text { Technological } \\
\text { competitiveness }\end{array}$} & \multirow{2}{*}{0.086} & 14 & Scenic spot website construction & 0.044 \\
\hline & & & 15 & Development of new tourism product & 0.042 \\
\hline & & \multirow{6}{*}{0.136} & 16 & Strategic positioning and long-term development planning & 0.022 \\
\hline & \multirow{5}{*}{$\begin{array}{l}\text { Management } \\
\text { competitiveness }\end{array}$} & & 17 & $\begin{array}{c}\text { Daily business management normalization, institutionalization, and } \\
\text { standardization }\end{array}$ & 0.022 \\
\hline & & & 18 & Staff management & 0.023 \\
\hline & & & 19 & Tourist management & 0.023 \\
\hline & & & 20 & Risk and crisis management & 0.0218 \\
\hline & & & 21 & Safety management & 0.0242 \\
\hline & \multirow{2}{*}{$\begin{array}{l}\text { Environment } \\
\text { competitiveness }\end{array}$} & \multirow{2}{*}{0.078} & 22 & Vegetation coverage & 0.04 \\
\hline & & & 23 & Garbage innocent treatment & 0.038 \\
\hline & \multirow{3}{*}{$\begin{array}{c}\text { Other } \\
\text { competitiveness }\end{array}$} & \multirow{3}{*}{0.14} & 24 & Degree of transportation convenience & 0.058 \\
\hline & & & 25 & Degree of consumption convenience & 0.052 \\
\hline & & & 26 & Degree of hospitality of local residents & 0.03 \\
\hline
\end{tabular}

Data source: collected according to Research on development, utilization and protection of landscape resources in Guilin ${ }^{[12]}$

The index weights were determined as follows.

A. Calculation of the total score of an index

Making $T_{\mathrm{i}}=\sum_{j=1}^{\mathrm{n}} x_{i j}, T_{i}$ is the total score of the $\mathrm{i}^{\text {th }}$ index ( $\mathrm{i}=26$ in this paper), $X_{i j}$ is the score of the $\mathrm{i}^{\text {th }}$ index obtained in the $\mathrm{j}^{\text {th }}$ sample, and $\mathrm{n}$ is the number of samples $(n=36$ in this paper).

B. Calculation of the total score of all indexes

$N=\sum_{i=1}^{n} T_{i}, N$ is the sum of score of all indexes, $T_{i}$ is the total score of the $\mathrm{i}^{\text {th }}$ index ( $\left.\mathrm{i}=26\right)$, and $\mathrm{n}$ is the number of samples $(\mathrm{n}=36)$.

C. Calculation of the index weight $U_{\mathrm{i}}=\frac{T_{\mathrm{i}}}{N},(\mathrm{I}=26)$,

$U_{i}$ is the weight of the $\mathrm{i}^{\text {th }}$ index ( $\left.\mathrm{i}=26\right), T_{i}$ is the total score of the $\mathrm{i}^{\text {th }}$ index $(\mathrm{i}=26)$, and $\mathrm{N}$ is the sum of score of all indexes. The results were shown in Table 3.2.

2) Analysis on Tourism Space Structure

With relevant data of statistical department and the subjective scoring data of the tourists as the original data, this paper calculated the standardized value of each index by the standardized range and calculated the score of each scenic spot according to the index evaluation system, as shown in Table 3.3.

Table 3.3. Statistics of Comprehensive Development Evaluation on Developed and Utilized Scenic Spots in Lingui District

\begin{tabular}{|c|c|c|c|c|c|c|}
\hline Scenic spot name & $\boldsymbol{W t}$ Town Mosque & $\begin{array}{l}\text { Former Residence } \\
\text { of Li Zongren }\end{array}$ & $\begin{array}{l}\boldsymbol{L} \boldsymbol{j} \text { Town Brick } \\
\text { Tower }\end{array}$ & $\begin{array}{l}\text { Bulwark of Shimendang } \\
\text { Village and Road } \\
\text { Monument For Village } \\
\text { Construction }\end{array}$ & $\begin{array}{l}\text { Bulwark of } \\
\text { Chucun Village }\end{array}$ & $\begin{array}{l}\text { Chastity Arch } \\
\text { of Mrs. Shi }\end{array}$ \\
\hline $\begin{array}{l}\text { Comprehensive } \\
\text { evaluation value }\end{array}$ & 6.22 & 27.34 & 3.21 & 3.68 & 3.77 & 2.89 \\
\hline Scenic spot name & $\begin{array}{l}\text { Shuangfeng } \\
\text { Bridge }\end{array}$ & Lt Mosque & Jixiang Bridge & $\begin{array}{l}\text { Hengshan Stone } \\
\text { Carving }\end{array}$ & $\begin{array}{l}\text { Xiongsen } \\
\text { Bear\&Tiger } \\
\text { Mountain } \\
\text { Village }\end{array}$ & $\begin{array}{c}\text { Dayan } \\
\text { Ancient } \\
\text { Cultural Relic }\end{array}$ \\
\hline $\begin{array}{l}\text { Comprehensive } \\
\text { evaluation value }\end{array}$ & 4.56 & 6.92 & 5.03 & 6.09 & 35.80 & 11.84 \\
\hline Scenic spot name & $\begin{array}{l}\text { Former Residence } \\
\text { of Bai Chongxi }\end{array}$ & $\begin{array}{l}\text { Snake King Li } \\
\text { Manor }\end{array}$ & $\begin{array}{l}\text { Xishan Stone Arch } \\
\text { Bridge (Xin Bridge) }\end{array}$ & $\begin{array}{c}\text { Maan Stone Arch } \\
\text { Bridge }\end{array}$ & $\begin{array}{l}\text { Xinglong } \\
\text { Bridge }\end{array}$ & Tong Bridge \\
\hline $\begin{array}{l}\text { Comprehensive } \\
\text { evaluation value }\end{array}$ & 18.41 & 29.36 & 4.33 & 4.85 & 4.74 & 4.29 \\
\hline
\end{tabular}




\begin{tabular}{|c|c|c|c|c|c|c|}
\hline Scenic spot name & Yugong Bridge & $\begin{array}{c}\text { Liu Sanjie Tea } \\
\text { Garden }\end{array}$ & $\begin{array}{c}\text { Former Site of } \\
\text { Provincial Normal } \\
\text { School in Guilin, } \\
\text { Guangxi }\end{array}$ & $\begin{array}{l}\text { Historic Buildings } \\
\text { Along The Ancient } \\
\text { Guilin-Liuzhou Canal }\end{array}$ & $\begin{array}{l}\text { Jiu Village } \\
\text { Mosque }\end{array}$ & $\begin{array}{l}\text { Diantou } \\
\text { Village Stone } \\
\text { Tower }\end{array}$ \\
\hline $\begin{array}{l}\text { Comprehensive } \\
\text { evaluation value }\end{array}$ & 4.62 & 52.72 & 14.72 & 8.09 & 6.81 & 3.76 \\
\hline Scenic spot name & $\begin{array}{l}\text { Roshan Lake } \\
\text { Water Park }\end{array}$ & Hengshan Village & Jiu Village & Yankou Village & $\begin{array}{l}\text { Shanwei } \\
\text { Village }\end{array}$ & $\begin{array}{l}\text { Flying Tiger } \\
\text { Heritage Park }\end{array}$ \\
\hline $\begin{array}{l}\text { Comprehensive } \\
\text { evaluation value }\end{array}$ & 81.87 & 14.64 & 14.23 & 13.97 & 12.02 & 19.24 \\
\hline Scenic spot name & $\begin{array}{l}\text { Huaping National } \\
\text { Nature Reserve }\end{array}$ & Butterfly Valley & Twelve Beach Drift & $\underset{\text { Lianhua Island Scenic }}{\text { Spot }}$ & $\begin{array}{l}\text { Yijiangyuan } \\
\text { Scenic Spot }\end{array}$ & $\begin{array}{c}\text { Hongxi } \\
\text { Scenic Spot }\end{array}$ \\
\hline $\begin{array}{l}\text { Comprehensive } \\
\text { evaluation value }\end{array}$ & 22.71 & 25.32 & 43.88 & 31.48 & 66.05 & 23.04 \\
\hline
\end{tabular}

Data source: collected according to Research on development, utilization and protection of landscape resources in Guilin ${ }^{[12]}$

The scenic spots in Table 3.3 were sorted by the score and divided into 5 levels according to the score, as shown in Table 3.4. Level 1: the comprehensive evaluation value $>80$. There is only one scenic spot at Level 1, that is, Roshan Lake Water Park Theme Park, which is the Level 1 growth pole of the development of tourism space. Level 2: $40<$ the comprehensive evaluation value $<80$. There are three scenic spots at Level 2, including Liu Sanjie Tea Garden, Twelve Beach Drift, and Yijiangyuan Scenic Spot, which are the Level 2 growth pole. Level 3: $20<$ the comprehensive evaluation value $<40$. There are seven scenic spots at Level 3, including Former Residence of Li Zongren, Xiongsen Bear\&Tiger Mountain Village, Snake King Li Manor, Huaping National Nature Reserve, Butterfly Valley, Lianhua Island Scenic Spot, and Hongxi Scenic Spot, which are the Level 3 growth pole. Level 4: $10<$ the comprehensive evaluation value $<20$. There are eight scenic spots at Level 4, including Dayan Ancient Cultural Relic, Former Residence of Bai Chongxi, Former Site of Provincial Normal School in Guilin, Guangxi, Hengshan Village, Yankou Village, Jiu Village, Shanwei Village, and Flying Tiger Heritage Park, which are the Level 4 growth pole with a certain attraction. Level 5: the comprehensive evaluation value $<10$. The scenic spots at Level 5 have weak attraction of tourists, which are the Level 5 growth pole with small contribution to the tourism.

3) Influence Mechanism

The following conclusions can be found through analysis on Table 3.4 .

(1) Theme park has a great influence on tourism space. For example, Roshan Lake Water Park Theme Park is Level 1 growth pole, which has been rated as National 4A Tourist Attraction after opening two years [13].

Table 3.4. Statistics of Growth Pole of Tourism Space in Lingui District

\begin{tabular}{|cl|}
\hline Level & Developed and utilized scenic spots \\
\hline Level 1 & Roshan Lake Water Park Theme Park \\
Level 2 & Liu Sanjie Tea Garden, Twelve Beach Drift, and Yijiangyuan \\
& Scenic Spot \\
Level 3 & $\begin{array}{l}\text { Former Residence of Li Zongren, Xiongsen Bear\&Tiger } \\
\text { Mountain Village, Snake King Li Manor, Huaping National }\end{array}$ \\
\hline
\end{tabular}

\begin{tabular}{|l|}
\hline Nature Reserve, Butterfly Valley, Lianhua Island Scenic Spot, \\
and Hongxi Scenic Spot \\
Dayan Ancient Cultural Relic, Former Residence of Bai \\
Chongxi, Former Site of Provincial Normal School in Guilin, \\
Guangxi, Hengshan Village, Yankou Village, Jiu Village, \\
Shanwei Village, and Flying Tiger Heritage Park \\
Wt Town Mosque, $\boldsymbol{L} \boldsymbol{j}$ Town Brick Tower, Bulwark of \\
Shimendang Village and Road Monument For Village \\
Construction, Bulwark of Chucun Village, Chastity Arch of \\
Mrs. Shi, Shuangfeng Bridge, Lt Mosque, Jixiang Bridge, \\
Level 5 Hengshan Stone Carving, Xishan Stone Arch Bridge (Xin \\
Bridge), Maan Stone Arch Bridge, Xinglong Bridge, Tong \\
Bridge, Yugong Bridge, Historic Buildings Along The Ancient \\
Guilin-Liuzhou Canal, Jiu Village Mosque, and Diantou \\
Village Stone Tower
\end{tabular}

Data source: collected according to Table 3.3

(2) The influence of natural landscape resources on tourism space is relatively great, while the influence of humanistic landscape resources on tourism space is relatively small. There are three scenic spots at Level 3, all of which belong to natural landscape resources; three are seven scenic spots at Level 3, of which three scenic spots belong to natural landscape resources and one belongs to humanistic landscape resource; the scenic spots at Level 4 and Level 5 belong to "site and relic" and "architecture and facilities", most of which are "temples, towers, bridges, and other buildings and structures".

(3) The cultural relic protection units of former residence and traditional villages have a certain influence on tourism space. Former Residence of Li Chongren and Former Residence of Bai Chongxi are national cultural relic protection unit and Guilin municipal cultural relic protection unit respectively and are listed in Level 3 and Level 4 respectively; Yankou Village, Hengshan Village, Jiu Village, and Shanwei Village are traditional villages at Level 4.

(4) Landscape resources at higher grade have a great influence on the tourism space as a whole. According to Table 3.1, Roshan Lake Water Park and Huaping Nature Reserve are at Grade I of Rating Results of Landscape Resources in $\mathbf{L g}$ District, Guilin City and at Level 1 and Level 3 of Results of Competitiveness Evaluation Index respectively; Twelve Beach Drift, Yijiangyuan Scenic Spot, Yankou Village, Hengshan Village, and Jiu Village are at Grade III, of which the first two are at Level 2 and the latter three are at Level 4. 


\section{Lingui District Tourism Space Structure Based on Landscape Resources Development and Utilization}

According to the research results of the classification and distribution of landscape resources, grade evaluation, evolution characteristics of tourism space structure, the influence of landscape resources development and utilization on tourism space structure, etc., and by combining with the trend of road, this paper constructed the space structure of "one ring, one core, one sub-core, and three axes" of tourism industry, as shown in Figure 4.1 .

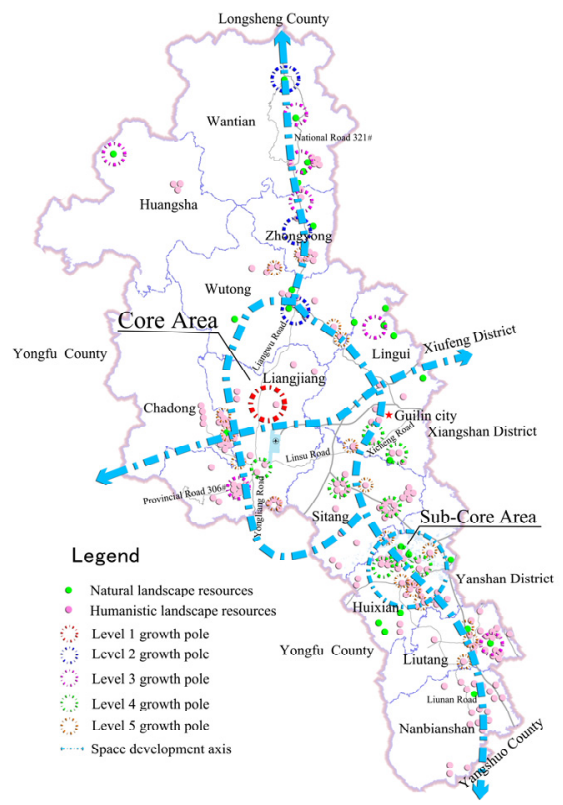

Figure 4.1. Lingui District Tourism Space Growth Pole Core and Regional Tourism Space Structure of One Ring, One Core, One Sub-core, and Three Axes

One ring, one core: one ring consists of the National Road 321 ${ }^{\#} \boldsymbol{W} \boldsymbol{t}-\boldsymbol{L} \boldsymbol{g}$ section, Xicheng Road, $\boldsymbol{S t}-\boldsymbol{N} \boldsymbol{b}$ Road $\boldsymbol{S t}$ section, Yongfu-Liangjiang Road Suqiai-Liangjiang section, and $\boldsymbol{L} \boldsymbol{j}-\boldsymbol{W} \boldsymbol{t}$ Road. On both sides of the ring, in addition to Liu Sanjie Tea Garden, the Level 1 growth pole of tourism space development, Former Residence of Li Zongren and Xiongsen Bear\&Tiger Mountain Village, the Level 3 growth pole of tourism space development, and Dayan Ancient Cultural Relic, Former Site of Provincial Normal School in Guilin, Guangxi, Hengshan Village, Yankou Village, and Flying Tiger Heritage Park, the Level 4 growth pole of tourism space development, there are also $\boldsymbol{L} \boldsymbol{j}$-Cd Agglomeration Zone and $\boldsymbol{S t}$ - $\boldsymbol{L g}$ Agglomeration Zone, having beautiful natural scenery and rich humanistic landscape resources, which is the core area of tourism space development.

One sub-core, and three axes: $\boldsymbol{H} \boldsymbol{x}$ Agglomeration Zone. There are beautiful scenery, rich humanistic landscape resources along the Ancient Guilin-Liuzhou Canal, the Grade I landscape resource-National Wetland Park (under construction), which is the largest karst wetland in Asia, and the Level 4 growth pole core of Former Residence of Bai Chongxi, Jiu Village, and Shanwei Village, which have great development potential. It is the secondary core area of tourism space development.

Three axes: the northern Yijiang Agglomeration Zone. There is beautiful scenery on both sides of Yijiang. Yao Nationality people live here together, bringing here distinct characteristics of Yao Nationality humanistic landscape resources. Relying on the development of Twelve Beach Drift and Yijiangyuan Scenic Spot of Level 2 growth pole, as well as National Road 321", extending northward to the world wonders-Longsheng Longji Terrace. That is the north vertical axis. In the northern $\boldsymbol{L} \boldsymbol{t}-\mathbf{N} \boldsymbol{b}$ Agglomeration Zone, the natural and humanistic landscape resources have equal shares; developing along the county road $-\boldsymbol{L t}-\boldsymbol{N} \boldsymbol{b}$ road, it extends southward to Chinese tourist county-Yangshou. That is the south vertical axis. There is $\boldsymbol{L} \boldsymbol{j}$ - $\boldsymbol{C d}$ Agglomeration Zone and $\boldsymbol{S t}$ - $\mathbf{L g}$ Agglomeration Zone in central area, extending eastward to Xiufeng District and Xiangshan District in Guilin City through Xicheng Avenue, and westward to Baishou scenic spot in Yongfu County through Linsu Road and Provincial Road 306". That is the horizontal axis.

\section{Conclusions and Suggestions}

1) There are a total of 257 scenic spots, covering 5 main categories, 14 sub-categories and 26 basic types, featured by diversified main categories and sub-categories, rich resources stock, humanistic landscape resources-based, and significant space agglomeration. There are $\boldsymbol{L} \boldsymbol{j}$ - $\boldsymbol{C d}$ Agglomeration Zone, St-Lg Agglomeration Zone, $\boldsymbol{H} \boldsymbol{x}$ Agglomeration Zone, and $\boldsymbol{L} \boldsymbol{t}-\boldsymbol{N} \boldsymbol{b}$ Agglomeration Zone.

2) Through evaluation and grade, the high-quality scenic spots reached a certain number, up to 11; the number of good scenic spots was more, up to 57; the number of ordinary scenic spots was the most, up to 189; high-quality and good landscape resources were distributed in aggregation.

3) As of 2015, the number of developed and utilized scenic spots was 36 , whose spatial distribution was concentrated and was dominated by humanistic landscape resources; among the developed and utilized landscape resources, there were seven natural scenic spots and 29 humanistic scenic spots, and the latter includes 22 cultural relic protection sites; there were 10 high-quality scenic spots having been developed, which have basically been developed; there were 15 good scenic spots and 11 ordinary scenic spots; for undeveloped scenic spots, there were 42 and 178 separately, having huge development potential. After the initial period of scattered-point spatial distribution, intensive period of scattered-point spatial distribution, and the formation period of point-axis space, they showed stepped and multi-center structure situation.

4) Through the comprehensive evaluation of development of scenic spots, we found that: 1) five levels of growth pole have been formed; 2) the influence mechanism of development and utilization of landscape resources on tourism space is: the influence of the theme park is the greatest, the influence of natural landscape resources is secondary and the influence of cultural landscape resources is the least, the former-residence-type cultural relics protection sites and 
traditional villages have a certain influence, and the influence of high-level landscape resources is big in general.

5) According to the above research results, we can build a tourism space structure of "one ring, one core, one sub-core, and three axes".

The above research results provide reference for the space development needs of landscape resources and the space development and layout of tourism in $\boldsymbol{L} \boldsymbol{g}$ District, and also provide idea for researching similar topics; however, this article is not involved in the development and utilization direction of landscape resources, namely, "one ring, one core, one sub-core, and three axes", pending further study. If something is wrong in this paper, it has nothing to do with others, and the author will be responsible for it.

\section{References}

1. Bihu Wu. Research on the Historical Geography of Tourist Area [J]. Journal of East China Normal University (Humanities and Social Sciences). 05,73-75(1994)

2. Jie Han. Discussion on Tourism Geographic Division in Northeast China [J]. Economic Geography. 04,72-76(1992)

3. Jiqian Zhang. Natural Tourism Resources and Its Development Plan of Loess Plateau Area [J]. Geography and Territorial Research. 03,60-64(1988)

4. Rong Zhao , Baoxiang Li. Discussion on Grand Tour and the Redevelopment of Tourism in Xi'an [J]. Economic Geography. 04,99-103(1999)

5. [5] Yaofeng Ma, Xiaodong Gou, JieYu. A Study on the Spatial Transfer Model of American and Canadian Tourists in and out of Xi'an [J]. Human Geography. 03,14-16(1999)

6. Liming Zhang. Discussion on the Strategic Layout of Tourism in Three Gorges Reservoir Area of Yangtze River [J]. Economic Geography. 03,117-120(2000)

7. Guoping Li. The Influence of the Three Gorges Project on Tourism Spatial Pattern of the Three Gorges [J].Geography and Territorial Research. 04,35-43(2001)

8. Weiqiang Liu. Study on the Spatial and Temporal Structure of Dali Tourist Area [J]. Scientia Geographica Sinica. 01,78-84(1993)

9. Jigang Bao, Haiyan Zheng, Guangjin Dai. The Evolution of Spatial Structure of Guilin's Domestic Tourist Market [J]. Acta Geographica Sinica. 01,96-105(2002)

10. Zhimei Tian. The Structure and Optimum Relocation of Territorial Tourism System in Shanxi Province [J]. Resources \& Industries. 04,61-63(2005)

11. General Administration of Quality Supervision, Inspection and Quarantine of the People's Republic of China. Classification , Investigation and Evaluation of Tourism Resources [M]. 2003

12. Zhengmin Wen, Fan Zhang, Jie Shi, Peng Yin et al Research on development, utilization and protection of landscape resources in Guilin[R]. 2017

13. http://baike.baidu.com/link?url=NxvL9zivZDA PTsixh7xb7UNRfo-5FAptqGknOt512JyxiwRE2p0 Qfb8zW7YFI7UbeXoSYRM-6bx14N4IvuCFKru MMoNh5PdP-fCT8WZV1Jy5jLGtrSmwMozJ_eR3 kZ7I1uqeYHvaFU5eZvDY4iBDb72IP4fW_6q07rX RRezcFi.

14. Rongdian Li, GuangqiuGan. Lingui County Annuals [M]. Local Records Publishings. Beijing: 1996

15. Statistics Bureau of Lingui County. Statistical Annual Report of Lingui County[R].1978-2015. 